\title{
ON THE ALLOCATION OF SOCIAL STRATA AND MILITARY ELITE IN THE EARLY SARMATIAN SOCIETY OF THE LOWER VOLGA REGION IN THE $4^{\mathrm{TH}}-3^{\mathrm{RD}} \mathrm{CC} . \mathrm{BC}^{1}$
}

\author{
Vladimir I. Moiseev \\ Volgograd State University, Volgograd, Russian Federation \\ Valentina Yu. Chistobaeva \\ Volgograd State University, Volgograd, Russian Federation
}

\begin{abstract}
Introduction. Studying the processes of genesis and development of nomadic peoples on the territory of steppe Eurasia in the early Iron Age demonstrates the complexity and multifacetedness of their political and social organization. The archaeological materials accumulated over the past decades and revealing the presence of social markers in funerary-memorial complexes, have led to an increase of interest in the study of the social structure of ancient societies, in the identification of specific historical features of the formation and functioning of social strata. Methods. The comprehensive methodology has been used for revealing social strata in ancient societies. It allowed carrying out the thorough statistical analysis of the full range of archaeological monuments on this topic and revealing the different levels of social differentiation reflected in material culture. Analysis. To examine the social structure of the Early Sarmatian society and to allocate the military nomadic elite, the materials of 143 funerals from burial mounds of the Lower Volga region have been analyzed. Results. The undertaken research allows asserting that the early Sarmatian society of the Lower Volga region in the $4^{\text {th }}$ - beginning of the $3^{\text {rd }}$ centuries $\mathrm{BC}$ had not been strictly stratified.

Key words: Early Iron Age, social structure, Early Sarmatian culture, military elite, migration processes, Lower Volga region, funeral ceremony, the set of weapons.

Citation. Moiseev V.I., Chistobaeva V.Yu. On the Allocation of Social Strata and Military Elite in the Early Sarmatian Society of the Lower Volga Region in the $4^{\text {th }}-3^{\text {rd }} \mathrm{cc}$. BC. Vestnik Volgogradskogo gosudarstvennogo universiteta. Seriya 4, Istoriya. Regionovedenie. Mezhdunarodnye otnosheniya [Science Journal of Volgograd State University. History. Area Studies. International Relations], 2018, vol. 23, no. 4, pp. 23-29. (in Russian). DOI: https://doi.org/10.15688/jvolsu4.2018.4.3
\end{abstract}

УДК 902.3

ББК 63.4(2)
Дата поступления статьи: 24.04.2018

Дата принятия статьи: 16.06 .2018

\section{К ВОПРОСУ ВЫДЕЛЕНИЯ СОЦИАЛЬНЫХ ГРУПП И ВОИНСКОЙ ЭЛИТЫ В РАННЕСАРМАТСКОМ ОБЩЕСТВЕ НИЖНЕГО ПОВОЛЖЬЯ IV - НАЧАЛА ІІІ в. ДО н. э. ${ }^{1}$}

\author{
Владимир Иванович Моисеев \\ Волгоградский государственный университет, г. Волгоград, Российская Федерация \\ Валентина Юрьевна Чистобаева \\ Волгоградский государственный университет, г. Волгоград, Российская Федерация
}

Аннотация. Изучение процессов генезиса и развития кочевых народов территории степной Евразии в эпоху раннего железного века демонстрирует сложность и многогранность их политической и обществен- 
ной организации. Накопленные за последние десятилетия археологические материалы, четко выявившие наличие в погребальных комплексах социальных маркеров, вызвали возрастание интереса к вопросу изучения социальной структуры древних обществ, выявлению конкретно-исторических особенностей формирования и функционирования социальных страт. В.И. Моисеев в данной работе отвечал за исследование археологических материалов, выделение социальных маркеров, статистический анализ выявленных социальных групп и интерпретацию полученных результатов. В.Ю. Чистобаева ответственна за выделение социальных маркеров, интерпретацию выявленных социальных групп в контексте археологических и этнографических источников.

Ключевые слова: ранний железный век, социальная структура, раннесарматская культура, военная элита, миграционные процессы, Нижнее Поволжье, погребальный обряд, набор вооружения.

Цитирование. Моисеев В. И., Чистобаева В. Ю. К вопросу выделения социальных групп и воинской элиты в раннесарматском обществе Нижнего Поволжья IV - начала III в. до н. э. // Вестник Волгоградского государственного университета. Серия 4, История. Регионоведение. Международные отношения. - 2018. T. 23, № 4. - C. 23-29. - DOI: https://doi.org/10.15688/jvolsu4.2018.4.3

\section{Введение}

Наибольшую трудность при реконструкции социальной стратификации вызывает практически полное отсутствие данных письменной традиции об общественных отношениях в раннесарматском обществе. Использование сведений погребальной обрядности, поиск этнографических аналогий позволяет с определенной долей вероятности восстановить социальную структуру изучаемого общества. В данной статье определены маркеры для определения социальных групп, в том числе отнесенных к дружинной аристократии, затронуты вопросы определения социальных страт, выделения воинской элиты и источников ее формирования на материалах погребального обряда раннесарматских племен в археологических памятниках Нижнего Поволжья IV начала III в. до н. э.

\section{Материалы и методы}

Многолетние результаты исследований, в которых выделялись основные элементы социальной структуры кочевников, и история изучения данной проблематики отражены в работах С.М. Абрамзона, Н.Н. Крадина, Г.Е. Маркова, Т.С. Султанова, А.М. Хазанова и др., носящих этнографический характер $[1 ; 2 ; 7 ; 8$; $9 ; 10 ; 13 ; 14 ; 15]$.

Определяя методику выявления социальных слоев в археологии, был использован комплексный подход, позволивший с помощью статистического анализа всесторонне охватить весь массив археологических памятни- ков по данной теме и выявить различные уровни социальной дифференциации, отраженные в материальной культуре. Несмотря на различия в погребальном обряде, учитывались следующие критерии: время сооружения курганов, величина и состав насыпи, количество погребений одного периода, место данного погребения, положение погребений в плане кургана, надмогильное сооружение, находки в насыпи, конструкции внутри могильной ямы, форма и величина могильной ямы, обряд погребения, количество погребенных, их пол и возраст, ориентировка погребенных, поза погребенных, ритуальные вещества, кости животных и предметы в могиле: посуда, оружие, украшения.

Целый ряд представленных характеристик, таких как ориентировка, расположение костяка в могильной яме, наличие напутственной пищи, являются обрядовыми чертами всей раннесарматской культуры и не играют особой роли при выявлении социальных групп.

Наряду с этим требовал рассмотрения вопрос о характере разрушения множества погребальных комплексов, было ли оно связано с разграблением или с определенными ритуальными действиями. В такой ситуации необходимо обратить пристальное внимание на способ проникновения в могилы. Так, например, ритуальное проникновение со смещением, изъятием отдельных костей или вещей из погребения в комплексе с другими данными о ритуале захоронения и его сложности позволяют предположить нерядовой статус погребенного [17, с. 88]. 
Для рассмотрения социальной структуры раннесарматского общества и выделения военной кочевой элиты к анализу привлекались данные 143 погребений из курганных могильников Нижнего Поволжья.

\section{Анализ}

Типичной характеристикой исследуемых курганных памятников является преобладание курганов-кладбищ. Эта традиция захоронения проникла на территорию Нижневолжского региона из Приуралья, где такой обряд сложился значительно раньше. Одним из ярких примеров является курганный могильник Лятошинка, курганы 1 и 5 которого с полным основанием можно считать курганами-кладбищами одного коллектива. Об этом свидетельствуют и традиция кольцевого расположения могил по отношению к центру - погребальный обряд, при котором сооружались камеры, и набор сопутствующего инвентаря, представленный хронологически и типологически близкими вещами. Схожая система расположения отражена в могильниках Новоузенск (кург. 1 и 2) и Эльтон (кург. 10).

УтверждениеБ.Ф. Железчикова и А.В. Фалалеева о небольшом сроке функционирования курганов как кладбищ позволяет рассматривать их как семейные коллективные усыпальницы [3, с. 41].

B.M. Клепиков также отмечает принадлежность курганов-кладбищ отдельным клановым сообществам, включающим в себя несколько линиджей. Число семей, входящих в микролиниджи, было незначительным, что обусловливается спецификой подвижного образа жизни скотоводов-номадов, которые кочевали вместе или поблизости друг от друга. Формы впускных погребальных захоронений, как и относительное их расположение, по мнению автора, могли маркировать разные статусы и родовые связи. Размеры курганов, сооруженных исключительно для членов раннесарматского общества, были небольшими, что позволяло даже незначительному количеству соплеменников собственными силами возвести его, в то время как для захоронения в более ранние курганы выбирались насыпи больших размеров [5, c. 47].
Исследование конструктивных особенностей показало, что все анализируемые курганы представляют собой, как правило, округлые насыпи, имеющие земляную структуру (более 95 \%). Выявление более высокого социального статуса погребенного в них возможно в тех случаях, когда погребение является основным и курган возводился исключительно для данного человека, а также, если для впускного центрального погребения выбирался выделяющийся на общем фоне своими размерами курган, сооруженный в более раннее время.

Среди основных захоронений IV - начала III в. до н. э. на территории Нижневолжского региона преобладают погребения мужчин (9 из 13 основных погребений, у которых удалось определить половую принадлежность).

Преобладание мужских захоронений среди всей совокупности (более $42 \%$ костяков, в том случае, когда был выявлен пол погребенного) может свидетельствовать сразу о некоторых особенностях жизни ранних сарматов. В первую очередь это может отражать специфику погребального обряда раннесарматского населения, при котором под курганами погребались не все члены общества. Также вполне возможно, что для отдельных групп, в том числе и половозрастных, существовали другие места погребений. Это может являться еще одним критерием, объясняющим преобладание мужских захоронений.

В.М. Клепиков в своей работе «Сарматы Нижнего Поволжья в IV-III вв. до н. э.» отмечает, что процесс миграции IV в. до н. э. имел характер переселения избыточной части населения в свободные области [4, с. 133]. Преобладание мужских погребений, сопровождаемых различными видами вооружения, составляет более $85 \%$ от всех мужских погребений исследуемой выборки. Можно предположить, что переселение носило немирный характер и затрагивало в большей степени мужскую часть населения [12, с. 121-130]. Это обусловливается особенностями кочевого общества, перемещение которого на новые территории осуществлялось зачастую мужчинами, ставившими под свой контроль местное население. Преобладание мужских погребений, сохранившееся на протяжении двух 
исследуемых веков, подтверждает идею B.M. Клепикова о непрерывном характере миграционных процессов [4, с. 138].

Анализ вещевого материала, сопровождающего погребальный обряд ранних сарматов, позволил выделить следующие маркеры социального статуса:

1. Мужские захоронения: набор вооружения (длинные и средние мечи, кинжалы, наконечники копий, железные черешковые и втульчатые, бронзовые втульчатые стрелы), оселки, являвшиеся, вероятно, частью военной экипировки, портупейные наборы, включавшие в себя ворворки, пряжки и колчанные крючки.

2. Женские захоронения: зеркала, украшения (бусы, браслеты, серьги, перстни), пряслица, курильницы, единичные предметы вооружения.

3. Для детских захоронений: редкие случаи находок сосудов, украшений, пряжек, напутственной пищи.

Встречаемость в мужских погребениях атрибутов женского погребального обряда и наоборот может иметь целый ряд причин: курильницы в мужских погребениях, вероятно, обладали ритуальным значением, украшения могли являться элементами костюма, единичные наконечники стрел в женских погребениях играли роль амулетов, оселки у женщин несли утилитарную функцию (заточка орудий труда). Как для мужских, так и для женских и детских погребений характерно наличие сосудов и напутственной пищи.

На основании характеристик погребального обряда захоронений раннесарматской культуры IV-III вв. до н. э. можно выделить три основных уровня, которые отличаются сопроводительным инвентарем.

Первая категория - безынвентарные захоронения или могилы со скудным инвентарем, составляющие $20 \%$ от общего количества исследуемых погребений. Вероятно, погребенные имели низкий имущественный и социальный статус в обществе. Выявить типовой набор вещей, характеризующих данную категорию, не представляется возможным ввиду отсутствия стандарта в наборе. Данные захоронения можно отнести к представителям низшего уровня социальной дифференциации при их жизни, таким как обедневшие члены общества.
Второй уровень наиболее многочисленный, составляет 68 \% от общего числа погребений. Захоронения включают в себя разнообразный погребальный инвентарь: лепные сосуды, орудия труда и небогатые украшения. Процентное соотношение погребений выявленного уровня дифференциации, в том случае, когда удалось определить половозрастную принадлежность, выглядит следующим образом.

В большинстве случаев (около 47 \% случаев данной категории) это мужчины, возраст которых составляет 30-40 лет.

Женские погребения этой категории (составляющие 32 \%) включают в себя предметы быта, такие как нож, лепные сосуды, а также зеркала, украшения, но отсутствует заупокойная пища. Для женщин возраст представительниц данной категории составляет приблизительно 35-45 лет. Детский погребальный инвентарь представлен жертвенной пищей или орудиями труда, а также лепными сосудами. Эта возрастная категория является самой малочисленной.

Учитывая как данные археологии, полученные при исследовании курганных могильников Нижнего Поволжья, так и данные этнографии относительно стратификации кочевых обществ, можно предположить, что представители данной прослойки общества относятся к рядовым независимым скотоводам, являвшимся полноправными членами кочевого раннесарматского общества и различающимся имущественным положением.

Последний уровень социальной дифференциации - это захоронения, вероятно, относящиеся к элитной прослойке общества (12\% от общего числа погребений). Их курганы чаще подвергались разграблению. В случае, когда насыпи оставались нетронутыми, погребения сопровождались разнообразным инвентарем, оружием, обильной заупокойной пищей.

Погребальный инвентарь различных половозрастных групп данной категории разнится. Возраст женщин, которых можно отнести к вышеназванной прослойке раннесарматского общества, находится в пределах от 30 до 45 лет и примерно совпадает с мужским.

Детские погребения также характеризуются наличием вооружения, сосудами, орудиями труда и украшениями. Необходимо отме- 
тить, что среди этой категории большинство захоронений подросткового возраста и не было обнаружено ни одного погребения младенцев. Вероятно, это связано со спецификой мировоззрений ранних сарматов и с тем, что ребенок еще не успел пройти обряд инициации, а, следовательно, не принадлежал еще данному обществу и этому миру. Одним из таких обрядов перехода и отождествления ребенка с этим миром является наречение или узнавание истинного имени ребенка $[6$, с. 68]. Возможно, поэтому детей, не достигших определенного возраста, хоронили со скудным вещевым комплексом.

Вещевой материал богатых мужских погребений представлен как вооружением, бронзовыми котлами, так и жертвенной пищей. Можно сказать, что основными признаками социального статуса у мужчин могут служить наличие набора вооружения, бронзового котла и золотых украшений. Представители этой категории могли являться военачальниками и выполнять культовые функции.

На фоне всей совокупности погребений данной категории выделяются мужские погребения с набором вооружения, включающим меч, колчан со стрелами и копье (Эльтон, кург. 10 погр. 9; Могута, кург. 8 погр. 3; Барановка, кург. 27 погр. 1; Венгеловка, кург. 2 погр. 10). Данная категория погребений составляет $8 \%$. Этот набор вооружения может быть атрибутом особой воинской элиты, он обнаруживает сходство с воинской экипировкой элиты кочевников Южного Приуралья [16, c. 16-23]. Наличие в погребениях этой группы глиняной посуды с тальком в тесте, мечей переходного типа, с дуговидным или изогнутым под тупым углом перекрестием, диагональных погребений, типичных для южноуральских кочевников, может свидетельствовать о принадлежности этой социальной группы к той группировке кочевников, которая непосредственно причастна к завоеванию Нижнего Поволжья.

\section{Результаты}

Проведенное исследование позволяет утверждать, что раннесарматское общество Нижнего Поволжья в IV - начале III в. до н. э. не является строго стратифицированным.
Наличие в воинских погребениях Поволжья комплекта вооружения - меча, колчанного набора и наконечника копья позволяет говорить о значимой роли тяжеловооруженных всадников в составе сарматской конницы, которые могли осуществлять сложные тактические маневры. Общие черты в экипировке с воинами южноуральской территории позволяют говорить о взаимосвязях этих двух регионов, протекающих не всегда мирно, поэтому наличие ударного кулака в виде воиновдружинников давало определенное преимущество в освоении новых земель племенным объединениям с Южного Приуралья. Продвижение в IV в. до н. э. ранних сарматов, находящихся на стадии своего формирования, с востока на запад до Нижнего Дона привело к окончательному их закреплению в III в. до н. э. на территории степного Поволжья [11, с. 19-20, 27].

Также возможно, что в милитаризованном кочевом обществе, в котором военный успех становился «социальным лифтом» для наиболее сильных и дисциплинированных представителей коллективов, появление воинской элиты, организованной в дружины, объединенной не только знатным происхождением, но и верностью «вождю», было основным орудием противостояния внешнему противнику. Обострение политической ситуации на данной территории и формирование военно-политического уклада с более упорядоченной структурой привело к возникновению сильных кочевых организаций, а также сформировало кочевые группы с возросшей властью вождей или специальные военные отряды, что и нашло отражение в археологическом материале.

Более детальное рассмотрение погребального обряда в дальнейшем позволит не только уточнить маркеры и уровни социальной структуры, но и реконструировать с учетом этнографических данных, как статус военной кочевой элиты, так и выяснить источники ее формирования. Наиболее перспективным в этой связи является вопрос соотношения местного и пришлого компонента с территории Южного Приуралья, нашедший отражение не только в материальной культуре, но и в трансформации уровней социальной дифференциации. 


\section{ПРИМЕЧАНИЕ}

1 Работа выполнена в рамках Государственного задания Минобрнауки РФ (проект № 33.2830.2017/4.6 «Юг России в эпоху раннего железного века: диалог культур Восток - Запад»).

\section{СПИСОК ЛИТЕРАТУРЫ}

1. Абрамзон, С. М. Формы родоплеменной организации у кочевников Средней Азии / С. М. Абрамзон // Родовое общество. Этнографические исследования и материалы : сб. ст. - М. : Изд-во АН CCCP, 1951.-260 c.

2. Абрамзон, С. М. Киргизы и их этногенетические и историко-культурные связи / С. М. Абрамзон. - Л. : Наука, 1971. - 404 с.

3. Железчиков, Б. Ф. Раскопки у с. Лятошинка / Б. Ф. Железчиков, А. В. Фалалеев // Археолого-этнографические исследования в Волгоградской области : сб. науч. ст. - Волгоград : Перемена, 1995. - С. 23-61.

4. Клепиков, В. М. Сарматы Нижнего Поволжья в IV-III вв. до н. э. / В. М. Клепиков. - Волгоград : Изд-во ВолГУ, 2002. - $216 \mathrm{c.}$

5. Клепиков, В. М. К вопросу о возможностях социальной интерпретации раннесарматского общества Нижнего Поволжья / В. М. Клепиков // Вестник Волгоградского государственного университета. Серия 4, История. Регионоведение. Международные отношения. - 2015. - Т. 35, № 5. - С. 46-52. DOI: http://dx.doi.org/10.15688/jvolsu4.2015.5.5

6. Коробкова, Е. А. Половозрастные особенности погребального обряда поздних сарматов (по материалам могильников Есауловского Аксая) / Е. А. Коробкова // Погребальный обряд ранних кочевников Евразии. Материалы и исследования по археологии Юга России : сб. ст. Вып. ІІІ. - Ростов н/Д, 2011.-С. 66-68.

7. Крадин, Н. Н. Кочевые общества (Проблемы формационной характеристики) / Н. Н. Крадин. - Владивосток : Дальнаука, 2005. - 239 с.

8. Крадин, Н. Н. Кочевники Евразии / Н. Н. Крадин. - Алматы : Дайк-Пресс, 2007. -414 с.

9. Марков, Г. Е. Кочевники Азии. Структура хозяйства и общественной организации / Г. Е. Марков. - М. : Наука, 1976. - 318 с.

10. Марков, Г. Е. Социальная структура и общественная организация древних и средневековых кочевников / Г. Е. Марков // Материалы Первой Всесоюзной археологической конференции. - Кемерово : Изд-во КГУ, 1980. - С. 21-29.

11. Скрипкин, А. С. Гибель Скифии. Сарматский фактор / A. C. Скрипкин // STRATUM PLUS: ARCHAEOLOGY AND CULTURAL ANTHROPOLOGY. -2016. - № 3.-C. 17-31.
12. Скрипкин, А. С. Сарматы / А. С. Скрипкин. Волгоград : Изд-во ВолГУ, 2017. - С. 121-130.

13. Султанов, Т. И. Кочевые племена Приаралья в XV-XVII вв. (Вопросы этнической и социальной истории) / Т. И. Султанов. - М. : Наука, 1982. 278 c.

14. Хазанов, А. М. Социальная история скифов / А. М. Хазанов. - М. : Наука, 1975. - 334 с.

15. Хазанов, А. М. Кочевники и внешний мир / А. М. Хазанов. - Алматы : Дайк-Пресс, 2002. -604 с.

16. Яблонский, Л. Т. Вооружение раннесарматского воина (по материалам Филипповского-1 могильника) / Л. Т. Яблонский, И. В. Рукавишникова // Вооружение сарматов: региональная типология и хронология : докл. к VI Междунар. конф. «Проблемы сарматской археологии и истории». - Челябинск : Изд-во ЮУрГУ, 2007. - С. 16-23.

17. Яценко, С. А. Глава VI. Группы элиты у сарматов / С. А. Яценко // Элита в истории древних и средневековых народов Евразии. - Барнаул : Изд-во АлтГУ, 2015.-330 с.

\section{REFERENCES}

1. Abramzon S.M. Formy rodoplemennoy organizatsii u kochevnikov Sredney Azii [Forms of Tribal Organization of the Nomads of Central Asia]. Rodovoe obshchestvo. Etnograficheskie issledovaniya i materialy: sb. st. [Generic Society. Ethnographic Research and Materials: Collection of Articles]. Moscow, Izd-vo AN SSSR, 1951. 260 p.

2. Abramzon S.M. Kirgizy $i$ ikh etnogeneticheskie $i$ istoriko-kulturnye svyazi [The Kyrgyz People and Their Ethnogenetic, Historical and Cultural Context]. Leningrad, Nauka Publ., 1971. 404 p.

3. Zhelezchikov B.F., Falaleev A.V. Raskopki u s. Lyatoshinka [Excavations near the Lytoshynka Village]. Arkheologo-etnograficheskie issledovaniya $v$ Volgogradskoy oblasti: sb. nauch. st. [Archaeological and Ethnographic Research in the Volgograd Region: Collection of Scientific Articles]. Volgograd, Peremena Publ., 1995, pp. 23-61.

4. Klepikov V.M. Sarmaty Nizhnego Povolzhya vIV-III vv. do n. e. [The Sarmatians of the Lower Volga Region in the 4th - 3rd cc. BC]. Volgograd, Izd-vo VolGU, 2002.216p.

5. Klepikov V.M. K voprosu o vozmozhnostyakh sotsialnoy interpretatsii rannesarmatskogo obshchestva Nizhnego Povolzhya [On the Possibilities of Social Interpretation of Early Sarmatian Society in the Lower Volga Region]. Vestnik Volgogradskogo gosudarstvennogo universiteta. Seriya 4, Istoriya. Regionovedenie. Mezhdunarodnye otnosheniya [Science Journal of Volgograd State University. History. Area Studies. International Relations], 2015, 
vol. 35, no. 5, pp. 46-52. DOI: http://dx.doi.org/10.15688/ jvolsu4.2015.5.5

6. Korobkova E.A. Polovozrastnye osobennosti pogrebalnogo obryada pozdnikh sarmatov (po materialam mogilnikov Esaulovskogo Aksaya) [Sex and Age Peculiarities of the Funeral Rite of the Late Sarmatians (Based on the Materials of Burial Grounds of Esaulovsky Aksai)]. Pogrebalnyy obryad rannikh kochevnikov Evrazii. Materialy $i$ issledovaniya po arkheologii Yuga Rossii: sb. st. Vyp. III [Burial Rite of the Early Nomads of Eurasia. Materials and Research on Archaeology of the South of Russia. Collection of Articles. Iss. III]. Rostov-on-Don, 2011, pp. 66-68.

7. Kradin N.N. Kochevye obshchestva (Problemy formatsionnoy kharakteristiki) [Nomadic Societies (Problems of the Formation Characteristics)]. Vladivostok, Dalnauka Publ., 2005. 239 p.

8. Kradin N.N. Kochevniki Evrazii [Nomads of Eurasia]. Almaty, Dyke-Press Publ., 2007. 414 p.

9. Markov G.E. Kochevniki Azii. Struktura khozyaystva $i$ obshchestvennoy organizatsii [The Nomads of Asia. The Structure of the Economy and Public Organization]. Moscow, Nauka Publ., 1976. 318 p.

10. Markov G.E. Sotsialnaya struktura i obshchestvennaya organizatsiya drevnikh i srednevekovykh kochevnikov [Social Structure and Social Organization of Ancient and Medieval Nomads]. Materialy Pervoy Vsesoyuznoy arkheologicheskoy konferentsii [Materials of the First All-Union Archaeological Conference]. Kemerovo, Izd-vo KGU,1980, pp. 21-29.

11. Skripkin A.S. Gibel Skifii. Sarmatskiy faktor [The Death of Scythia. The Sarmatian Factor].
STRATUM PLUS: ARCHAEOLOGY AND CULTURAL ANTHROPOLOGY, 2016, no. 3, pp. 17-31.

12. Skripkin A.S. Sarmaty [The Sarmatians]. Volgograd, Izd-vo VolGU, 2017, pp. 121-130.

13. Sultanov T.I. Kochevye plemena Priaralya v $X V-X V I I v v$. (Voprosy etnicheskoy $i$ sotsialnoy istorii) [The Nomadic Tribes of the Aral Sea Region in the $15^{\text {th }}-17^{\text {th }} \mathrm{cc}$. (Issues of Ethnic and Social History)]. Moscow, Nauka Publ., 1982. 278 p.

14. Khazanov A.M. Sotsialnaya istoriya skifov [Social History of the Scythians]. Moscow, Nauka Publ., 1975. 334 p.

15. Khazanov A.M. Kochevniki i vneshniy mir [Nomads and the Outside World]. Almaty, Dyke-Press Publ., 2002. 604 p.

16. Yablonsky L.T., Rukavishnikova I.V. Vooruzhenie rannesarmatskogo voina (po materialam Filippovskogo-1 mogilnika) [The Armament of Early Sarmatian Warriors (Based on the Materials of the Filippovsky-1 Burial Ground)]. Vooruzhenie sarmatov: regionalnaya tipologiya $i$ khronologiya: dokl. k VI Mezhdunar. konf. "Problemy sarmatskoy arkheologii i istorii» [The Armament of the Sarmatians: Regional Typology and Chronology. Reports to the $6^{\text {th }}$ International Conference "Problems of Sarmatian Archaeology and History"]. Chelyabinsk, Izd-vo YuUrGU, 2007, pp. 16-23.

17. Yatsenko S.A. Glava VI. Gruppy elity u sarmatov [Chapter VI. The Sarmatian Elite]. Elita v istorii drevnikh $i$ srednevekovykh narodov Evrazii [Elite in the History of Ancient and Medieval Peoples of Eurasia], Barnaul, Izd-vo AltGU, 2015.330 p.

\section{Information about the Authors}

Vladimir I. Moiseev, Researcher, Laboratory for Archaeological Research, Volgograd State University, Prosp. Universitetsky, 100, 400062 Volgograd, Russian Federation, v.moiseev@volsu.ru, https://orcid.org/ 0000-0002-5110-733X

Valentina Yu. Chistobaeva, Laboratory Assistant, Laboratory for Archaeological Research, Volgograd State University, Prosp. Universitetsky, 100, 400062 Volgograd, Russian Federation, v.chistobaeva@volsu.ru,https://orcid.org/0000-0001-7946-3144

\section{Информация об авторах}

Владимир Иванович Моисеев, научный сотрудник лаборатории археологических исследований, Волгоградский государственный университет, просп. Университетский, 100, 400062 г. Волгоград, Российская Федерация, v.moiseev@volsu.ru, https://orcid.org/0000-0002-5110-733X

Валентина Юрьевна Чистобаева, лаборант лаборатории археологических исследований, Волгоградский государственный университет, просп. Университетский, 100, 400062 г. Волгоград, Российская Федерация, v.chistobaeva@volsu.ru, https://orcid.org/0000-0001-7946-3144 